\title{
A construção do olhar: \\ a Viagem à ltália, de Goethe
}

The Construction of the Look: Goethe's Italian Journey

Mirella Guidotti ${ }^{1}$

\begin{abstract}
This article investigates Johann Wolfgang von Goethe's Italian Journey, published in 1816-1817, which reports his travels through the Italian peninsula from 1786 to 1788 . More than a reconstruction of his traveling through memories and diaries, the Journey stands out as a narrative of a different look towards a piece of art, as a construction of Goethe's aesthetics.
\end{abstract}

Key-words: Goethe; Italian Journey; Aesthetics.

Resumo: Investiga-se a Viagem à Itália de Johann Wolfgang von Goethe, obra que narra a viagem à península italiana de 1786 a 1788, publicada em 1816-1817. Contudo, mais do que uma reconstrução de sua viagem através das memórias e diários, a Viagem importa, antes de mais, como uma narrativa da construção de um novo olhar para com a obra de arte, como a construção da própria estética goetheana.

Palavras-chave: Goethe; Viagem à Itália; Estética.

Ja! Das Auge trügt mich nicht!

Goethe, Faust.

O decorrer dos dois anos nos quais Johann Wolfgang von Goethe permaneceu na Itália (1786-1788) concretizou-se, décadas mais tarde (1816-1817), na obra Viagem à Itália. No início de sua jornada, sob a data de 6 de setembro de 1786, Goethe registra:

\footnotetext{
${ }^{1}$ Doutoranda no Programa de Estudos Literários. Universidade Estadual Paulista "Júlio de Mesquita Filho". Capes. Email: mirellaguidotti@gmail.com
} 
Guidotti, M. - A construção do olhar

Por volta das seis horas da manhã, eu estava em Munique e, depois de doze horas contemplando tudo à minha volta, quero fazer aqui apenas umas poucas observações. Na galeria de pintura, não me senti em casa; tenho, em primeiro lugar, de reacostumar meus olhos às pinturas. São quadros magníficos. Os esboços de Rubens na galeria de Luxemburgo proporcionaram-me grande alegria.

Encontra-se ali também a nobre peça que é o modelo da coluna de Trajano. A base em lápis-lazúli, as figuras, douradas. É sempre um belo trabalho, que se contempla de bom grado.

No salão dedicado à Antiguidade, pude notar bem que meus olhos não estão treinados para a contemplação de tais objetos, razão pela qual não quis perder tempo, demorando-me ali. Muita coisa não me atraiu nem um pouco, sem que eu soubesse dizer por quê (GOETHE 1999: 14).

Acompanharemos aqui a famosa Viagem, o que chamaremos de "renascimento" goetheano, processo que leva à constituição da estética do poeta. A própria produção do texto da Italienische Reise poderia corroborar esta linha de leitura, pois, não obstante tenha registrado a experiência durante toda a viagem, Goethe se debruça sobre seus apontamentos somente décadas mais tarde, em sua velhice, incorporando, como é necessário supor devido ao longo período que separa a experiência da viagem e a elaboração do relato, transformações aos registros, fazendo surgir assim uma estetização da própria existência. A produção posterior desta Viagem indica uma preocupação não satisfeita com o mero relato como registro da experiência, mas sim o desejo de dar ao mundo uma obra acabada, capaz de relatar a trajetória de transformação do narrador. $\mathrm{Na}$ carta enviada a Herder de Nápoles, última de sua experiência em terras italianas, quando Goethe já está em viagem de volta, o poeta faz uma alusão à impossibilidade de um relato propriamente dito:

Com muita frequência, porém, as observações revelam seu caráter lacunar, e se, para aquele que a realizou, a viagem parece passar feito um rio, surgindo em sua imaginação como um fluxo constante, sente-se então que um relato propriamente dito é impossível (GOETHE 1999: 497).

Adiante, respondendo calorosamente à ocupação de Herder com a Itália e a Sicília, bem como o interesse pelas leituras de relatos de viagem, Goethe se apressa em dizer que se Herder o tivesse manifestado anteriormente, “[...] teria sido ainda mais diligente do que 
Guidotti, M. - A construção do olhar

fui” (GOETHE 1999: 497), passagem na qual se entrevê a preocupação do narrador de manter o frescor, por assim dizer, de seu relato, não obstante sua publicação tenha ocorrido, como já alertado, somente décadas mais tarde.

A obra constitui, pois, um texto que combina as dicções da escrita de si e da narrativa de viagem, expondo o processo de formação do narrador e o nascimento de uma nova maneira de contemplar a obra de arte, que se propõe, por um lado, comunicar as impressões do viajante, e, por outro, constituir o próprio pensamento estético goetheano, mescla, por sinal, verificável em outros momentos da produção do autor, como, por exemplo, em sua autobiografia Aus meinem Leben. Dichtung und Wahrheit, para citar o exemplo mais evidente.

As alusões a um Goethe anterior à viagem e a um Goethe posterior à viagem são uma constante. Goethe crê "ter mudado até os ossos" (GoETHE 1999: 173), considera o dia em que chegou a Roma como a data de seu "segundo nascimento, "um verdadeiro renascimento" (GOETHE 1999: 175) e compara as idéias de outrora a "sapatinhos de criança” (GOETHE 1999: 177). No final do primeiro ano da Viagem, em 10 de novembro de 1786, Goethe sentencia: "Não estou aqui para gozar a vida a minha maneira; quero dedicar-me às grandes coisas, aprender e formar o espírito antes de chegar aos quarenta anos" (Goethe 1999: 167). Em 16 de março de 1787 Goethe diz ainda: "[...] mal me reconheço; pareço a mim mesmo uma pessoa totalmente diferente. Ontem, pensei comigo: 'Ou você era louco antes ou tornou-se agora'" (GOETHE 1999: 247). O nascimento do "novo Goethe" também está presente na nova identidade usada: como um arquiteto em viagem pela Itália, Goethe caminha como um desconhecido, tentando desvencilhar-se de sua fama e, poder-se-ia acrescentar, também de antigas idéias. A Viagem narra assim as profundas mudanças no desenvolvimento pessoal e intelectual, a ampla rede de transformações e aprendizados, proporcionada pela experiência direta com as obras de arte em solo italiano, a contemplação dos monumentos do Renascimento e da Antiguidade, mas também a observação acurada da paisagem e plantas, minerais e clima. A Viagem é pois, antes de mais, uma viagem ao interior de si mesmo, um relato do processo de construção do próprio narrador, de sua formação, sua Bildung. 
Guidotti, M. - A construção do olhar

Trecho exemplar no caminho de formação do narrador encontra-se no balanço feito pelo poeta do quanto aprendera, utilizando a figura do arquiteto como metáfora dos sólidos alicerces, no porvir de sua formação:

$\mathrm{O}$ renascimento que me transforma de dentro para fora segue seu curso. Por certo, eu acreditava que fosse aprender de verdade aqui; mas não pensei que fosse ter de voltar à escola primária, que precisaria desaprender, ou verdadeiramente reaprender tanto. Disso já me encontro agora convencido, tendo-me entregado por completo a esse aprendizado, e quanto mais me vejo obrigado a negar a mim mesmo, tanto mais me alegro. Sou como um arquiteto que, desejando construir uma ponte, deu-lhe uma fundação ruim; a tempo, apercebe-se disso e demole o quanto já erguera; busca, então, ampliar e aperfeiçoar seu projeto, dar-lhe alicerces mais seguros e compraz-se já, de antemão, da indubitável solidez da futura construção (GOETHE 1999: 178).

Uma indagação surge: como um texto que, a princípio, retrata somente experiências de viagens, pode constituir o pensamento goetheano sobre a arte, a ponto de o poeta se referir a esta experiência como uma volta à escola primária? Nesse caso, a indicação de algum tipo de resposta parece estar contida na própria pergunta, já que, como se aborda a seguir, a apreciação em ato do objeto de bela arte representará para Goethe quase uma exigência: sobretudo nessa Viagem, o órgão que guiará a apreciação da bela arte em sua caminhada pela Itália será, por excelência, a visão, as experiências visuais do espectador - no caso, do autor -, a associação direta com o objeto de arte.

A reflexão sobre a estética goetheana refere-se, portanto, fundamentalmente à percepção sensorial, à primazia da contemplação imanente. Nessa linha, Magali dos Santos MouRA aponta que o processo formativo goetheano

[...] está em íntima e essencial ligação com o desenvolvimento da capacidade sensorial que é para Goethe, em primeira instância, a capacidade visual. Nesse sentido a viagem é uma ode à sensualidade, não só no sentido de se verter ao gozo da visão, mas a entrega ao próprio processo de provocar, sob forma constante, a sensualização da realidade. Goethe estava ocupado em sentir o que está ao seu alcance, revelado pelo olhar (MOURA 2006: 151).

A alusão à importância concedida ao sentido da visão se apresenta também em outras ocasiões. Em Gespräche mit Goethe, Goethe teria dito à Eckermann “[...] a objetividade de minha poesia [...] devo à grande atenção e exercício do olhar” (ECKERMANN 1836: 
Guidotti, M. - A construção do olhar

$103)^{2}$ e na autobiografia Aus meinem Leben. Dichtung und Wahrheit, quando Goethe confere uma predominância do sentido da visão sobre os demais: o "[...] olho era entre todos os outros sentidos, o órgão pelo qual eu apreendia o mundo" (cf. GOETHE 1889: 16).

Na Viagem, essa noção se manifesta plasticamente através do uso recorrente de verbos que sugerem pela carga semântica, direta ou indiretamente, a importância do sentido da visão, da contemplação direta da obra de arte. Uma "[....] nova vida tem início quando se vê com os próprios olhos aquilo que, em parte, se conhece tão bem, por dentro e por fora" (GOETHE 1999: 149), diz Goethe. Nesta jornada, o poeta alemão fala também em “[....] fidelidade ao propósito de ter os olhos sempre límpidos" (Id.: 159) e afirma: quem com seriedade "[....] põe-se aqui a olhar em torno e tem olhos para ver, há de tornar-se sólido" (Id.). Essa concepção faz-se presente no correr de toda a Viagem, como no testemunho de 12 de Outubro de 1786, no qual Goethe diz que se não tivesse iniciado a viagem "[....] teria simplesmente perecido", a tal ponto em seu espírito o desejo de contemplar com os "[....] próprios olhos esses objetos de arte" havia amadurecido (GoETHE 1999: 116). Poucos dias adiante, Goethe diz ainda:

Quanta alegria e quanta compreensão devo às últimas oito semanas! Mas também meu esforço não foi nada pequeno. Mantenho os olhos sempre abertos e registro bem em minha mente tudo o que vejo. Julgar, não desejo, tanto quanto me é possível não fazê-lo (GOETHE 1999: 143).

Os breves excertos são elucidativos, pois sintetizam exemplarmente a idéia central que importa no presente texto. Após manifestar a alegria e admiração pelos conhecimentos proporcionados pela observação viva das obras de arte antigas e modernas, Goethe atém-se ao modo de conhecer as obras, valendo-se de termos que se referem ao sentido da visão. "Mantenho os olhos sempre abertos", "registro bem em minha mente tudo o que vejo", diz Goethe, e, menos explicitamente, quando sugere que a apreciação das obras deveria permanecer, por assim dizer, na retina: "Julgar, não desejo, tanto quanto me é possível não fazê-lo".

2 "Die Gegenständlichkeit meiner Poesie", sagte Goethe, “[...] bin ich denn doch jener großen Aufmerksamkeit und Übung des Auges schuldig geworden" (ECKERMANN 1836: 213). 
Guidotti, M. - A construção do olhar

Caminho semelhante encontra-se em Viagem de um alemão à Itália (17861788), de Karl Philipp Moritz - que, por sinal, encontrou-se com Goethe na Itália - na consideração da obra de arte. Ao considerar uma pintura de Ticiano, MoRITZ diz que "[...] o olho deve primeiro se acostumar a ser inteiramente olho, a se comportar com passividade, a não espreitar e a não investigar demasiadamente" a fim de que "[...] se procure o belo, que está aqui imediatamente diante dos olhos, não muito longe no âmbito da fantasia ou mesmo no pensamento" (MORITZ 2007: 35).

Ambos os autores partem, pois, da centralidade da questão do efeito, do sentimento estético gerado no espectador por meio da observação in loco das belezas artísticas e naturais, com os sentidos do olfato, visão e tato em alerta para contemplar a obra de arte, as impressões recebidas por meio do aparelho sensorial. O modo de apreciação artística goetheano representa nesse sentido um rompimento com o circuito de mídia de então, no qual a apreciação da arte ocorria somente por meio de cópias, desenhos de arquitetura, tratados e lembranças pessoais. Há assim uma quebra desse circuito: através da valorização da apreciação direta do objeto artístico ocorre uma profunda transformação da percepção, aisthêsis, do observador. Como advoga PURDY (2008), Goethe inaugura nesse sentido também uma nova postura na apreciação da bela arte, pois atribui importância à apreciação imanente, ao que surge fenomenicamente, ressaltando que o

[...] local tinha que ser questionado, os comentários críticos desafiados, cada estória antiga que se tenha ouvido sobre o lugar tinha de ser comparada com o que se viu diretamente. Este tipo de investigação pessoal tinha não somente o potencial de mudar o julgamento do espectador, mas também ameaçava reconfigurar fundamentalmente o observador que tão completamente se lançara para dentro do momento estético. Dentro deste novo modo subjetivo, o ceticismo em relação à literatura de turismo forneceu um dos mais fortes motivos para viajar. A desconfiança de toda representação tornou-se um motivo para abandonar o livro e ver por si mesmo, estabelecendo assim o indivíduo que vê como o árbitro definitivo do significado arquitetônico [...]. Enquanto Goethe configura sua motivação dentro da linguagem da experiência imediata, insistindo em sua singularidade, se torna claro no curso de sua viagem que seus julgamentos estão em dívida com os discursos estabelecidos da arquitetura e poética do século dezoito [...], a ordem clássica era menos importante para o século dezoito do que o sentimento evocado por uma construção (PURDY 2008: 58-60). 
Guidotti, M. - A construção do olhar

Como expressa o próprio Goethe na Viagem,

[...] louvava o bom gênio por ter-me permitido ver com meus próprios olhos aqueles restos tão bem conservados, uma vez que é impossível transmitir uma idéia deles por meio de qualquer reprodução. $\mathrm{E}$ isso porque, no desenho arquitetônico, eles parecem mais elegantes e, na representação em perspectiva, mais grosseiros do que são; é somente quando caminhamos à sua volta e através deles que lhes comunicamos vida de fato; sente-se neles essa vida, e isso é o que pretendeu o construtor [...] (GOETHE 1999: 261).

O encontro imediato com a obra de arte deve ser uma troca entre espectador e objeto contemplado, fazendo da experiência em terra italiana fundamentalmente um processo de conhecer a si mesmo pelo outro, concepção fundamentalmente circular, de solidariedade entre sujeito e objeto. Goethe reconfigura aqui toda uma postura ante o objeto de bela arte, a partir da contemplação direta do objeto artístico pelo observador, já que é através de uma observação empática que a arte terá de ser julgada; com efeito, o juízo de arte será resultado de um intercâmbio entre o objeto artístico e o espectador, pois é através do sentimento gerado no espectador a partir do contato direto com a obra, que se dá o juízo da arte. "Não estou fazendo esta maravilhosa viagem com o propósito de me iludir, mas sim de me conhecer melhor a partir dos objetos que vejo" (GoETHE 1999: 53), diz o poeta-pensador.

Segundo Goethe, para se apreender bem os objetos, não deve ocorrer imposição do sujeito. Como o poeta diz em uma Máxima, na “[...] observação da natureza, no maior como no menor, me faço incessantemente a pergunta: é o objeto ou é você, que aqui se exprime? (GoETHE 1991: 827). Como sugere Goethe, o conhecimento deve construir-se com os próprios objetos, na apreciação fenomenal. O espectador tem de deixar a obra de arte surgir diante dele, abandonando-se à contemplação do objeto. Há aqui inversão da contemplação alicerçada apenas na cognição - a apreciação do observador da obra de arte, numa via de mão única - para uma relação interdependente entre sujeito e objeto, uma via de mão dupla entre observador e objeto observado. Diante dessa concepção, não se pode submeter os fenômenos a julgamentos transcendentais pelo sujeito, atribuindo-lhes características que estes não possuem, o que rompe a concepção de conhecimento que possui no sujeito o epicentro do processo 
Guidotti, M. - A construção do olhar

de conhecimento, mesmo porque, aqui, o próprio espectador está em formação, o próprio espectador se transforma e se educa à medida que se entrega à apreciação da bela arte. A esse respeito WERLE aponta que o modo goetheano de pensar a subjetividade está de "[...] acordo com uma certa fenomenologia da produção artística, segundo a qual o artista se coloca num caminho de idas e vindas e sempre é localizado na relação com o objeto que lhe é correspondente e sem o qual ele não é nada" (WERLE 2009: 181).

A obra de arte mesma se apresenta ao observador, antes que qualquer pensamento objetivante intente subjugá-la ou explicá-la, pois o efeito gerado no espectador é traduzido primeiro no sentir que no pensar. Goethe parte do empírico para o conceitual, da atividade investigativa do olhar, da observação fenomênica das coisas, isento de juízos pré-estabelecidos, afastando-se das poéticas de acento normativo, dos conceitos ilusórios habituais. Goethe interpela a permanecermos na retina, a experienciar a obra de arte, aprendendo a arte de olhar, um olhar novo, livre, como que seduzido pela obra. "O fato de eu me ter agarrado e apegado tanto aos objetos propiciame agora uma inacreditável capacidade de, por assim dizer, tocar a música sem o auxílio da partitura" (GOETHE 1999: 378), diz Goethe.

Goethe não busca, pois, na teoria os instrumentos para a contemplação da arte, o poeta vai às próprias coisas. Em seu percurso de aprendizagem pelas terras italianas, essa concepção se faz sentir na não rara predileção pela experiência direta com as obras em detrimento de seu estudo nos livros, como a relação de Goethe com Palladio, o qual, não obstante seja admirado, é preterido pela comparação da experiência viva com as próprias obras de arte. Em 8 de Outubro de 1786, por exemplo, ao contemplar peças da Antiguidade na casa Farsetti, Goethe relata:

Muitos desses importantes bustos transportam-me para os magníficos tempos antigos. Infelizmente, porém, percebo o quanto meus conhecimentos são deficientes nesse campo; progredirei, por certo, pois ao menos sei o caminho para tanto. Palladio abriu-o para mim, assim como abriu-me também o caminho para toda a arte e toda a vida (GOETHE 1999: 104).

Semanas adiante, porém, Goethe discorda de seu conselheiro, e manifesta discordâncias com seu até então elogiado mentor, justamente porque Palladio provavelmente não 
Guidotti, M. - A construção do olhar

havia contemplado diretamente o templo de Minerva, o que explica a representação incorreta da obra. Exaltado diante do templo, diz Goethe:

Sim, pois fui mais uma vez obrigado a constatar quão deficiente é a tradição. Palladio, em quem sempre me fiei, apresenta, é certo, um desenho desse templo, mas não há de tê-lo visto pessoalmente, pois assenta-o sobre pedestais de fato, o que confere às colunas uma altura desproporcional, dando origem a um monstro repelente, semelhante ao de Palmira, em vez de um aspecto tranqüilo e adorável, oferecendo satisfação aos olhos e ao intelecto (GOETHE 1999: 138).

Exemplar neste sentido é também o seguinte excerto da Viagem:

Interessam-me agora tão-somente as impressões captadas pelos sentidos, e estas livro algum, pintura alguma oferece. $\mathrm{O}$ fato é que meu interesse pelo mundo se renova; testo meu poder de observação e examino até onde vão minha ciência e meus conhecimentos, se meus olhos estão limpos e vêem com clareza, quanto posso apreender em meio à velocidade, e se as rugas sulcadas e impressas em meu espírito podem ser de novo removidas. Já neste momento, em que estou por minha própria conta, em que preciso estar sempre atento e presente, dão-me esses poucos dias ao espírito uma elasticidade inteiramente nova; tenho de me preocupar com o câmbio, trocar dinheiro, pagar, fazer anotações, escrever eu próprio, em vez de, como antes, apenas pensar, querer, refletir, ordenar e ditar (GOETHE 1999: 30).

Goethe diz que agora se interessa "tão-somente" pelas "impressões captadas pelos sentidos", acrescentando ainda que "livro algum", poderia oferecer. Goethe testa então seu "poder de observação" e interroga "até onde" alcançam sua ciência e conhecimento, se seus olhos podem novamente ver com clareza, por debaixo das "rugas sulcadas e impressas" em seu espírito. Índice do interesse goetheano pelo mundo e pela apreciação direta com as coisas apresenta-se também nas atividades cotidianas enumeradas a seguir, as preocupações com o câmbio, pagamentos e anotações em terra italiana, em contraposição à vida na Alemanha, concentrada nas atividades apenas de "pensar, querer, refletir, ordenar e ditar". A apreciação nascida da experiência é pois enriquecida pelos olhares, tatos e cheiros, em sutilezas não apreensíveis de outro modo, impossíveis de se converterem em um mero documento abstrato.

A intensa percepção sensualista da fase italiana faz-se presente no lirismo das Römische Elegien, originalmente intituladas Erotica Romana, publicadas logo após 
Guidotti, M. - A construção do olhar

Goethe retornar da Itália (1788-1790). Na elegia de número VII, tal valorização é exemplar:

O wie fühl' ich in Rom mich so froh! gedenk' ich der Zeiten,

Da mich ein graulicher Tag hinten im Norden umfing,

Trübe der Himmel und schwer auf meine Scheitel sich senkte,

Farb- und gestaltlos die Welt um den Ermatteten lag

Und ich über mein Ich, des unbefriedigten Geistes

Düstre Wege zu späh'n, still in Betrachtung versank.

Nun umleuchtet der Glanz des helleren Äthers die Stirne;

Phöbus rufet, der Gott, Formen und Farben hervor.

Sternhell glänzet die Nacht, sie klingt von weichen Gesängen,

Und mir leuchtet der Mond heller als nordischer Tag.

Welche Seligkeit ward mir Sterblichem! [...]

(GOETHE-AUSGABE 1795: 242) ${ }^{4}$.

O Norte é descrito sempre em tonalidades acinzentadas e opacas - o poema fala em um "cinzento dia", em um "sombrio e pesado céu que sobre mim se abatia", em um mundo "sem cor e forma", no qual "me afundo em observações silenciosas do espírito insatisfeito". Em contraposição ao norte sombrio, contrapõe-se então Roma, onde o Eulírico sente-se "muito feliz", e as tonalidades são aqui sempre claras e brilhantes contrastando visualmente o acinzentado-sombrio do Norte, e Roma, onde há o "brilho do luminoso éter" que lhe "ilumina a face", no qual "Febo, o deus, excita as formas e cores", e onde "Brilham as claras estrelas da noite, ressoando ternas canções". A oposição entre o Norte e Roma se manifesta, pois, através do contraste entre as cores, no contraste entre os elementos da natureza traduzidos numa polaridade, a noite e o dia, o escuro e o claro, a tristeza representada pelos tons acinzentados-escuros do Norte "graulicher", “trübe”, “schwer”, “farblos”, “gestaltlos”, “düstre” - e a luminosidade e intensidade de cores em Roma - "helleren" presentes a partir do sétimo verso, também

\footnotetext{
${ }^{4}$ Encontra-se uma tradução em Leoni: "Como em Roma me sinto feliz se penso naquele tempo, quando a luz cinzenta do Norte me envolvia! Sentia que sôbre a cabeça a abóbada celeste era obscura e oprimente; e o mundo, sem mais forma e côr, vivia cansado ao meu redor. Ficava a meditar, longe e em silêncio, para espiar os mais tristes caminhos do espírito inquieto. Agora, o relâmpago do ar puro me envolve a fronte e o deus Febo me exalta as cores e as formas. A noite resplandece estrelada, ressoa de doces canções e do alto do céu a lua me ilumina mais que nórdico sol. Quanta alegria divina foi concedida a um mortal! [...]" (GOETHE 1967: 11).
} 
Guidotti, M. - A construção do olhar

nos verbos e substantivos: "umleuchtet", "glänzet”, "leuchtet”, “Glanz”, “Äther”, "Formen und Farben" e "sternhell". A oposição tem seu ápice quando o poeta declara que a lua, em Roma, ilumina mais que o sol nórdico: "Und mir leuchtet der Mond heller als nordischer Tag”. (Id.)

A plasticidade apresentada na contraposição entre Norte e Roma, poder-se-ia dizer, são índices da valorização de Roma, local por excelência da saudação da vida, da entrega aos sentidos. Em Viagem à Itália, a 8 de outubro de 1786, a contraposição entre Alemanha e Itália retorna. Goethe afirma que o olhar do pintor veneziano por certo era privilegiado, pois ele fora educado a ver tudo, desde a infância, com "maior clareza e limpidez":

É evidente que os olhos se formam em consonância com os objetos que divisaram desde a infância, e, sendo assim, o pintor veneziano há de ver tudo com maior clareza e limpidez do que os outros homens. Nós, que vivemos numa terra ora imunda, ora poeirenta, incolor, a obscurecer qualquer reflexo, muitos até, talvez, em cômodos apertados, não podemos, por nós próprios, desenvolver uma visão assim jubilosa (GOETHE 1999: 102).

Cumpre lembrar que na Italienische Reise essa contraposição também se apresenta entre Roma e Caserta. Quando de sua estada em Caserta, Goethe diz: "Se, em Roma, o que se deseja é estudar, aqui se quer apenas viver; esquecemo-nos de nós mesmos e do mundo, e causa-me uma sensação peculiar conviver tão-somente com pessoas dispostas a gozar a vida" (GOETHE 1999: 248-249). Poucos dias adiante, porém, o contraponto torna a ser entre a Alemanha e a Itália, no caso, Nápoles:

Não fosse pela índole alemã e pelo desejo de aprender e fazer sempre mais, em vez de gozar a vida, eu talvez devesse permanecer por mais algum tempo aqui, nesta escola do viver com leveza e alegria, buscando tirar dela maior proveito (GOETHE 1999: 258).

O acento sensualista na apreciação estética goetheana não esbarra, todavia, em uma concepção negativa sobre a possibilidade (e necessidade) de apreender os objetos artísticos. Goethe possui ainda um traço marcadamente científico. Nesse sentido, através do sentido do ver, Goethe não confere somente predominância a um determinado órgão da percepção, como o poeta expressara na autobiografia Aus meinem 
Guidotti, M. - A construção do olhar

Leben. Dichtung und Wahrheit. A predominância do sentido da visão para Goethe funda, ainda, o modo de conhecer, o conhecimento sensualista do mundo. Na obra Farbenlehre, essa concepção de conhecimento é marcante: Goethe diz "O ouvido é mudo, a boca é surda; mas o olho ouve e fala. Nele se reflete de fora, o mundo, de dentro, o homem. A totalidade do interior e exterior se realiza através do olho" (GOETHE 1906: 12).

A ciência estética goetheana se traduz, pois, na procura de um método diverso de apreender a obra de arte, o qual exige ferramentas diferentes, que se dirijam não apenas ao intelecto. Goethe não aceita teorizações que não partam da apreciação da própria obra de arte, porém, um momento posterior é igualmente almejado. A teoria surge a partir do contato com a obra, não antes dela, surge do particular, não do geral. Um método, em resumo, que parte das particularidades (da contemplação imanente), objetivando alcançar uma abstração de outro nível: "Uma vez, porém, visto o objeto, então se poderá com prazer ler e ouvir a seu respeito, pois a isso juntar-se-á a impressão viva; somente aí é que poderá refletir e julgar" (GOETHE 1999: 183), diz Goethe. O poeta avança, assim, no empreendimento de uma teoria de conhecer (e apreciar) o belo, traduzida na possibilidade de apreender cientificamente o Todo nas Partes, temática, por sinal, bastante recorrente na obra goetheana segundo Magali dos Santos MOURA: o “[...] enigma do eterno (divino) contingenciado no instantâneo é um tema sempre recorrente em Goethe e se faz pela saída do momento ligado à singularidade e a ligação a um eterno, atemporal e universal" (MOURA 2006: 121).

A atitude científica goetheana funda-se, portanto, prioritariamente, na observação, ao que se anuncia ao olhar do espectador no primeiro momento, na percepção imediata do objeto artístico, encontrando aqui o sentido etimológico do termo estética, derivada do grego aisthêsis, que significa percepção, apreender com os sentidos.

Essa posição já se manifesta, por sinal, em um texto de juventude, Von deutscher Baukunst, de 1772, no qual Goethe diz ter a "[...] cabeça cheia de conhecimentos gerais do bom gosto", juízo que também sugere o extrapolar do discurso acadêmico, auferido somente nos livros. Assim descreve Goethe a fachada da catedral de Estrasburgo 
Guidotti, M. - A construção do olhar

Quando fui pela primeira vez à catedral, eu tinha a cabeça cheia de conhecimentos gerais do bom gosto. Eu louvei a harmonia das massas e a pureza das formas por ouvir falar, era um inimigo declarado das arbitrariedades confusas dos adornos góticos. Sob a rubrica "gótico", semelhante a um verbete de dicionário, juntei todos os mal-entendidos sinonímicos, termos como indeterminado, desordenado, inatural, agregado, remendado, sobrecarregado, que sempre vinham à minha cabeça. Nada mais sensato do que um povo que designa todo o mundo estranho de bárbaro, que chama tudo o que não cabe em seu sistema de gótico, desde os bonecos e figuras torneadas com que os nossos cidadãos honrados adornam as suas casas até os sérios restos da arquitetura alemã mais antiga, sobre a qual, por causa de alguns rabiscos aventureiros, afinei com o coro geral: "Totalmente esmagada pelo adorno!" Assim, ao prosseguir meu caminho, fiquei apavorado diante da visão de um mostro disforme e encrespado. Mas, com que sentimento inesperado fui surpreendido pela visão quando cheguei diante dela! Uma impressão total e grandiosa preencheu a minha alma, impressão que eu certamente pude saborear e desfrutar mas não conhecer e esclarecer, porque consistia em milhares de particularidades harmoniosas entre si (GOETHE 2008: 43).

O texto Von deutscher Baukunst tem assim na impressão imediata da catedral, livre de qualquer juízo aprioristicamente determinado, seu acento: Goethe recusa a apreensão segundo normas abstratas no modo de julgar a arquitetura, a apreensão atenta às regras impostas pela tradição estética, em favor de uma fruição atenta ao efeito emotivo e transformador gerado no espectador. No comentário da obra Itália, de Archenholz ${ }^{2}$, esse posicionamento também se manifesta. Goethe diz: "Como se encolhe todo um tal livrinho quando se está aqui, como se o colocássemos sobre carvão em brasa e ele fosse pouco a pouco se tornando marrom, depois preto, as folhas retorcendo-se e virando fumaça" (GOETHE 1999: 172).

Na quinta elegia, a via sensualista também é exemplar:

Froh empfind' ich mich nun auf klassischem Boden begeistert;

Vor- und Mitwelt spricht lauter und reizender mir.

Hier befolg' ich den Rat, durchblättre die Werke der Alten

Mit geschäftiger Hand, täglich mit neuem Genuß.

Aber die Nächte hindurch hält Amor mich anders beschäftigt;

Werd' ich auch halb nur gelehrt, bin ich doch doppelt beglückt.

\footnotetext{
${ }^{2}$ Trata-se da obra England und Italien, de Johann Wilhelm von Archenholz, publicada em 1785. Muito lida em sua época, a obra fazia uma comparação entre o comportamento cultural e os modos de vida da Inglaterra e da Itália.
} 
Guidotti, M. - A construção do olhar

Und belehr' ich mich nicht, indem ich des lieblichen Busens

Formen spähe, die Hand leite die Hüften hinab?

Dann versteh' ich den Marmor erst recht; ich denk' und vergleiche,

Sehe mit fühlendem Aug', fühle mit sehender Hand [...]

(GOETHE-AUSGABE 1795: 239) ${ }^{6}$.

Nos quatro primeiros versos ressoa já a atmosfera sensualista dessa quinta elegia. O Eulírico, "sente-se feliz em terra clássica", e com "zelosas mãos" folheia "as obras antigas, observando dia a dia um novo prazer". Com a chegada de Amor à noite, incitando a "outros afazeres", a atmosfera sensualista intensifica-se: "me torno somente pela metade douto", diz o poeta, porém "duplamente me alegro", equação que sugere a predileção da esfera sensível. Essa sugestão, contudo, não se confirma, já que adiante, as duas instâncias parecem convergir: o poeta pergunta então retoricamente, "e acaso não me instruo com os belos seios e com as formas de seus quadris?" e acrescenta: "então compreendo o mármore finalmente, reflito e comparo, e vejo com olho que sente, sinto com mão que vê". Há aqui oposição com a mera apreensão cognitiva da obra de arte, privilegiando um intercâmbio entre apreensão intelectual e a apreensão imanente do objeto artístico. $\mathrm{O}$ entendimento está unido à sensação, necessita da apreciação direta, do contato com o fenômeno e se conhece através dessa relação, a qual agrega impressão sensorial e pensamento, a perfeita correspondência entre as faculdades intelectuais e a faculdade dos sentidos, a satisfação proporcionada "aos olhos e ao intelecto" (1999: 138), para lembrar novamente Goethe.

A nova apreensão da arte originada com o "renascimento" goetheano exige assim a experiência viva da obra de arte, mediada principalmente pelo sentido do ver. Contudo, segundo Magali dos Santos MourA, a contemplação imanente da obra de arte e o sentimento decorrente dessa apreciação possui plena validade: a "[...] aparência, o que é captado pelos sentidos liga-se assim à verdade, à essência, ao conceitual e o jogo

\footnotetext{
6 "Aqui, nesta clássica terra, alegro-me: o mundo antigo e o moderno me falam com doces e claras palavras. Aqui sigo o preceito, e com álacre mão folheando as obras antigas, experimento agora um novo prazer. Mas, de noite, Amor me atrai a outros afazeres: não serei completamente douto, em compensação duplamente me sinto feliz. Não aprendo, talvez, se olho os belos seios ou se modelo ligeiramente com a mao os seus flancos? Só naquele momento compreendo o mármore, reflito, comparo e vejo com olhar que sente e sinto com mão que vê [...]" (GoETHE 1967: 9-10).
} 
Guidotti, M. - A construção do olhar

entre interior e exterior, entre observador e objeto de estudo é digno de seriedade" (MOURA 2006: 133).

Goethe faz da apreciação sensualista dos objetos artísticos, portanto, o próprio alicerce de seu pensamento estético e possui, nesse sentido, um viés bastante particular: não se caracteriza por uma teoria estética propriamente dita, no sentido de estabelecer regras e juízos aprioristicamente; porém, por outro lado, é possível identificar em seus escritos certa constante, a qual sugere que a própria teoria estética goetheana, se assim se pode chamar o pensamento goetheano sobre a arte, se dá por uma via sensualista. Esta, vale lembrar, constituiu-se justamente através das circunstâncias proporcionadas em sua Viagem à Itália, através da experiência individual e do contato com o ambiente artístico no qual se situara.

\section{Referências bibliográficas}

ECKERMANN, J. P. Gespräche mit Goethe in den letzten Jahren seines Lebens, 1823 - 1832. Leipizig: Brodhaus 1836.

GoEthe, J. W. Viagem à Itália. São Paulo: Cia. Das Letras 1999. . Escritos sobre arte. Introdução, tradução e notas de Marco Aurélio Werle. São Paulo: Humanitas/ Imprensa Oficial do Estado de São Paulo 2008. . Maximen und Reflexionen. In: Werke. Band 17. München, Wien: Carl Hanser 1991. . Elegias Romanas. São Paulo: Quaderni della rassegna brasiliana di studi italiani 1967. . Aus meinem Leben. Dichtung und Wahrheit. In: Werke. 27 Band. I Abteilung. Weimar: Hermann Böhlau 1889.

. Farbenlehre. In: Werke. 5 Band. II Abteilung. Weimar: Hermann Böhlau Nachfolger, 1906.

MORITZ, K. P. Viagem de um alemão à Itália. Tradução, introdução e notas de Oliver Tolle. São Paulo: Imprensa oficial do Estado de São Paulo 2007.

Moura, M. dos S. A Poiesis orgânica de Goethe: a construção de um diálogo entre arte e ciência. Tese de Doutorado, USP, São Paulo 2006.

PURDY, D. L. The Building in Building: Goethe, Palladio, and the Architectural Media. In: Goethe Yearbook. Vol 15, 2008, p. 57-73.

Werle, M. A. Arte e filosofia no Idealismo Alemão. Barcarolla: São Paulo 2009.

GOETHE AUSGABE - http://goethe.chadwyck.co.uk/ 